\title{
Fouling study of Nanofiltration membranes for sugar control in grape must. Analysis of resistances and the role of osmotic pressure
}

\author{
C. Salgado ${ }^{1}$, F.J. Carmona ${ }^{2}$, L. Palacio ${ }^{1}$, A. Hernández ${ }^{1}$, P. Prádanos ${ }^{1}$ \\ ${ }^{1}$ Grupo de Superficies y Materiales Porosos (SMAP, UA-UVA-CSIC), Dpto. de Física Aplicada, \\ Facultad de Ciencias, Universidad de Valladolid, 47071 Valladolid, Spain. \\ ${ }^{2}$ Dpto. de Física Aplicada. Esc. Politécnica. Universidad de Extremadura, 10003. Cáceres, \\ Spain.
}

\section{Abstract}

Three membranes are analyzed attending to their retention, flux and fouling when used to nanofiltrate sugars in red grape musts. With high molecular weight compounds, fouling develops from initial pore blocking to final cake deposition. A decrease of resistance appears due to a decrease of the effective transmembrane pressure and cake compaction. The final effective pore size corresponds to that of the compacted cake.

Attending to flux decay and sugar retention, two membranes, $\mathrm{HL}$ and SR3, are appropriate to reduce the content of sugar of red must. Specifically SR3 shows the best passage of sugar and less fouling.

Keywords: Must nanofiltration, Fouling, Osmotic pressure, Cake Compaction, Pore size 


\section{Introduction.}

Membrane technology has been increasingly used in the beverage industry. For example, it is considered as an alternative concentration method of grape must ${ }^{[1]}$. This plays an important role in the beverage and wine industry since it contributes to the preservation of must and the concentrate is a natural sweetener in wine production, and a vitamin- and aroma-rich drink.

If the molecular weight of sugars in must is taken into account, nanofiltration, NF, is the membrane process to be chosen to retain them. It has been successfully used to increase the sugar content of grape must (to increase the final alcohol degree) in wine production ${ }^{[2]}$. Using a two stage NF process of grape must, Versari et al. ${ }^{[2]}$ obtained relatively high sugar retentions (7-97\%). Moreover, in their work García-Martin et al. ${ }^{[3,4]}$ studied the sugar reduction in musts by a two stage nanofiltration process to obtain wines with a slight alcohol reduction.

One of the main difficulties of NF technology is membrane fouling. Fouling in general causes deterioration in permeate quality and quantity, and eventually leads to an is unavoidable membrane replacement ${ }^{[5]}$.This is because the dominant fouling mechanism in NF processes is the formation of a layer (a "cake") that can significantly degrade membrane performance ${ }^{[6]}$. The conventional cake filtration theory consists form a corpus developed by Ruth ${ }^{[7]}$ and successive researchers ${ }^{[8-12]}$. This approach states that during filtration, the cake thickness increases with time. In most cases, it also becomes more compact and its resistance to fluid flow increases accordingly. The main features of the dynamic behavior of cake filtration are the variation of the cake thickness, the evolution of the cake structure, the specific cake resistance and the total filtrate for a specified set of operating conditions ${ }^{[13,14]}$.

Fouling mechanisms during membrane filtration processes (i.e. Micro, MF, and Ultrafiltration, UF) have been studied in deepness along the last century ${ }^{[15-20]}$. Subsequently, Schippers and Verdow ${ }^{[21]}$ studied the mechanisms involved during the performance of Reverse osmosis, RO. More recently, Listiarini et al. 
$[5,22]$ applied these mechanisms for the analysis of the fouling of NF membranes.

In our previous work ${ }^{[23]}$, a method was proposed to allow studying individually the resistances and fouling mechanism generated by low and high molecular weight solutes, LMW and HMW respectively, in red grape must NF.

The aim of the present work is to analyze in deepness the fouling mechanism, osmotic pressure and resistances of different NF membranes during the filtration of commercial grape must. Moreover, the assessment of these results and their influence on the performance of the NF membranes will conduct to the selection of the most appropriate one for sugar control in grape must.

For this purpose, the methodology suggested in previous studies ${ }^{[23]}$ was applied in order to analyze individually the influence of LMW and HMW compounds.

\section{Theory.}

\subsection{Permeate flux decrease and retention model.}

When the overall filtration process is taken into account, the flux through the membrane per unit of membrane area can be written in terms of the applied transmembrane (hydraulic) pressure, $\Delta p_{h, s}$, the osmotic pressure gradient, $\Delta \pi_{s}$, the viscosity of the solution that goes through the pores of the membrane, $\eta_{p}$, and the system resistance. This is the sum of the membrane resistance, $R_{m}$, and the terms that depend on the fouling caused by the LMW, $\mathrm{R}_{f L M W}$, and the HMW, $\mathrm{R}_{f H M W}$, solutes ${ }^{[24-27]}$. In this way the permeate flow, $J_{v}$, can be calculated as

$$
J_{v}=\frac{\Delta p_{h, s}-\Delta \pi_{s}}{\eta_{p}\left(R_{m}+R_{f}\right)}=\frac{\Delta p_{h, s}-\Delta \pi_{s}}{\eta_{p}\left(R_{m}+R_{f L M W}+R_{f H M W}\right)}
$$


Since the concentration of ionic species (potassium, calcium, sodium and magnesium) is similar on both sides of the membrane and the concentration of organic acids is much lower than that of sugars ${ }^{[23]}$, the increase of osmotic pressure can be determined by taking only into account the contributions of glucose and fructose by means of the van't Hoff's law:

$\Delta \pi_{s}=\sum_{i=1}^{N} \Delta \pi_{s, i}=\sum_{i=1}^{N} \frac{\mathrm{R}}{M_{i}}\left(C_{\mathrm{m} i}-C_{\mathrm{p}, i}\right)$

Here, $M_{i}$ is the molar weight of the $i$-th component, $\mathrm{N}$ is the number of components contributing to the osmotic pressure drop through the membrane system (here $\mathrm{N}=2$ and $\mathrm{i}$ is glucose and fructose), $R$ the gas constant and $T$ the temperature. $C_{m, i}$ and $C_{p, i}$ are the concentrations on the membrane system interfaces at the feed and permeate sides respectively.

Figure 1 depicts the different concentrations and osmotic pressures to be considered along the membrane system.

\section{Figure 1}

\subsection{Fouling mechanisms.}

Compared to the solute size, NF membranes are provided with pores of a very small size. Hence, fouling mechanisms where it is assumed that all the solute molecules plug a pore (complete blocking); or are deposited inside the pores (standard blocking) seem inappropriate. Rather, molecules could deposit on other previously settled on the membrane surface or directly plug a pore as assumed in the so called intermediate blocking. Therefore, for the synthetic solution nanofiltration, so as for the first steps of must nanofiltration, flux decay should be caused by the intermediate blocking mechanism according to ${ }^{[19,20]}$.

$\ln J_{v}(t)=-\kappa_{i} \frac{V_{p}(t)}{A_{m}}+\ln J_{V, 0}$

where $\kappa_{i}$ is the intermediate blocking kinetic constant in $\mathrm{m}^{-1}, V_{\mathrm{P}}$ is the permeated volume in $\mathrm{m}^{3}$ and $A_{m}$ the membrane surface area in $\mathrm{m}^{2}$. 
After saturation of the intermediate mechanism, a cake would eventually be built. According to this model the time evolution of the process will be given by:

$\frac{t}{V_{\mathrm{P}}(t)}=\frac{\kappa_{\mathrm{c}}}{2} V_{\mathrm{P}}(t)+\frac{1}{J_{v, 0} A_{m}}$

where the kinetic constant $\kappa_{c}\left(\right.$ in $\left.\mathrm{s}^{-\mathrm{m}^{-6}}\right)$ is twice the Modified Fouling Index ${ }^{[21]}$, $\mathrm{MFI}$, that is defined as the slope of the plot of $t / V_{P}$ versus $V_{P}$.

\subsection{Pressure drops along the membrane system.}

As mentioned, in cake filtration mechanisms such as grape juice filtration, the feed passes through two contributions to the overall resistance that are placed in series: that of the membrane and that of the layer formed due to the fouling (cake).

In the same way, the effective applied pressure drop, the hydraulic pressure applied and the osmotic pressure through the membrane system at any time should be the sum of the contributions in the membrane and the cake. Then:

$\left.\begin{array}{l}\Delta p_{e f f, s}=\Delta p_{e f f, m}+\Delta p_{e f f, c} \\ \Delta p_{h, s}=\Delta p_{h, m}+\Delta p_{h, c} \\ \Delta \pi_{s}=\Delta \pi_{m}+\Delta \pi_{c}\end{array}\right\}$

Where:

$$
\left.\begin{array}{l}
\Delta p_{\text {eff }, s}=\Delta p_{h, s}-\Delta \pi_{s} \\
\Delta p_{e f f, m}=\Delta p_{h, m}-\Delta \pi_{m} \\
\Delta p_{e f f, c}=\Delta p_{h, c}-\Delta \pi_{c}
\end{array}\right\}
$$

Therefore, according to Eq. (1), each effective pressure can be calculated as

$$
\Delta p_{e f f, k}=J_{v} \eta_{P} R_{k} \quad k=s, m \text { or } c
$$

Now we need to know $\Delta \pi_{k}$ to get $\Delta p_{h, k}$ or vice versa from data on the resitances. 
According to Eq. (2) we can get $\Delta \pi_{c}$ once the concentration at the membrane-cake interface, $C_{m, i}$, is known. The other contributions to the total osmotic pressure drop are easily accessible as far as they refer to the feedcake and the membrane-permeate interfaces. But, according to the definition of the true retention of the solutes, $R_{i}$ (i.e. glucose and fructose) ${ }^{[23]}$ :

$C_{m, i}=\frac{C_{p, i}}{1-R_{i}}$

When these calculations are done for the synthetic solution $C_{m, i}$ is the concentration of glucose or fructose on the membrane active layer because no cake would appear. $C_{m, i}$ can be calculated with Eq. (8) if it is accepted that the membranes sugars true retention is equal to that evaluated for the synthetic solution filtration and that it behaves in the same way when the cake appears as when it is not present. Eq. (2) also allows us to evaluate both $\Delta \pi_{m}$ and $\Delta \pi_{s}$. Then, by Eqs. (6) and (7), $\Delta p_{h, k}$ can be calculated. Then all the terms of pressure drops along the membrane system could be evaluated by using Eqs. (5) and (6).

\subsection{Specific cake resistance. Principles of cake filtration.}

The cake sheet formed over the membrane consists in a thin layer of solid particles through which the permeate flows. The specific cake resistance represents the fouling resistance caused by the fouling layer on the membrane, $R_{f}$, normalized by the accumulated cake mass per unit of membrane area ${ }^{[22]}$, so $\alpha=\frac{R_{f} A_{m}}{m_{c}}$

Thus, according to Eq. (1) for the cake:

$$
\alpha=\frac{\Delta p_{\text {eff,c }} A_{m}}{\eta_{p} J_{v} m_{c}}
$$

where $m_{c}$ is the mass of the cake deposited on the membrane surface. 
A material balance allows the correlation of $m_{c}$ with the permeate volume $V_{P}$ (volume collected up to time $t$ ). If $C_{b}$ is the bulk concentration of foulants, the mass of the particles deposited onto the membrane can be correlated to the permeated volume as

$$
m_{c}=\gamma V_{p} C_{b}
$$

where $\gamma$ is a particle deposition factor (less than unity) that accounts for the reduction of cake mass due to its partial removal induced by the crossflow conditions. This coefficient was first proposed, by Sioutopoulos et al. ${ }^{[28]}$, in order to extrapolate specific cake resistance calculations to cross flow conditions. Therefore Eq. (9) could be used to evaluate $\alpha$ if $C_{b}$ is known, and Eq. (10) can be used to get $\Delta p_{\text {eff,c }}$.

In order to calculate $C_{b}$ along the filtration process, the following assumptions must be made:

1. The global concentration of foulants is considered to be that of the total dry extract of must, $C_{D E}$, which includes all matter that is non-volatile. This concentration was defined and determined in accordance to the OIV methods ${ }^{[29]}$. These procedures require weighting at a temperature of 70 ${ }^{\circ} \mathrm{C}$ under vacuum of $25 \mathrm{mmHg}$ until measuring a constant weight.

2. All the HMW compounds are always retained by the membrane; therefore the mass of these particles in the retentate side, $m_{H M W}$, is considered to be constant during the process.

3. Only the variation of the concentrations of glucose and fructose in the retentate were taken into account since their concentration is so high that the variation of the other LMW is considered negligible.

In accordance to these ideas, the concentration of HMW can be obtained as

$C_{H M W}=C_{D E}-C_{T, 0}$

where $C_{T, 0}$ is the initial total sugar concentration (glucose and fructose). Moreover

$m_{H M W}=C_{H M W} V_{0}$ 
$V_{0}$ being the initial volume of must.

Finally, $C_{b}$ can be evaluated, as a function of time, by

$C_{b}(t)=\frac{m_{H M W}+m_{T R}(t)}{V_{R}(t)}$

where $m_{T R}(t)$ is the total sugar content and $V_{R}(t)$ the volume of the retentate at the filtration time $t$. Then, by using Eqs. (11) and (7), Eq. (10) can be used to calculate $\alpha$.

Another strategy could be used for the estimation of $\alpha$. In effect, according to Eqs. (1), (4) and (10), $\kappa_{c}$ (that can be determined from the flux kinetics according to

$$
\kappa_{c}=\frac{\gamma \eta_{p} C_{b} \alpha}{A_{m}^{2} \Delta p_{e f f, s}}
$$

where, $\Delta p_{\text {eff,s }}$ is known because $\Delta \pi_{\mathrm{s}}$ can be evaluated by eq. (2).

\subsection{Pore size evolution.}

Apparent pore size can be used to study flux decay through the analysis of its evolution. In order to estimate pore size, the Donan Steric and Partitioning model was used, with the introduction of the applied pressure gradient term as has been previously described ${ }^{[30]}$. In these terms, the retention coefficient that a NF membrane presents can be written as

$$
R=1-\frac{K_{\mathrm{c}} \phi}{1-\left(1-K_{\mathrm{c}} \phi\right) e^{-P e}}
$$

In this expression, the steric partition coefficient is $\phi=\left(1-r_{i} / r_{p}\right)^{2}$ if a cylindrical geometry is assumed for the pores, being $r_{i}$ and $r_{p}$ the i-th component and pore radii respectively. The dimensionless $P$ eclet number is given by:

$$
P e=\frac{K_{\mathrm{c}} J_{V}}{K_{\mathrm{d}} D_{\mathrm{i}}}\left(\frac{\Delta x}{A_{k}}\right)=\frac{K_{\mathrm{c}} J_{V}}{K_{\mathrm{d}} D_{i}}\left(\frac{r_{\mathrm{p}}^{2}}{8 L_{\mathrm{p}} \bar{\eta}}\right)
$$


where $L_{p}$ is the water permeability, $\bar{\eta}$ the viscosity inside the pore, and $\Delta \mathbf{x}$ and $A_{k}$ are the thickness and porosity of the membrane respectively. $K_{c}$ and $K_{d}$ represent the hindrance factors for convection and diffusion, respectively. These were evaluated as proposed by Dechadilok and Deen ${ }^{[31]}$ :

$$
\begin{aligned}
& K_{d}=\frac{1}{(1-\lambda)^{2}}\left[\begin{array}{l}
1+\frac{9}{8} \lambda \ln \lambda-1.56034 \lambda+1.91521 \lambda^{3}-2.81903 \lambda^{4}+0.270788 \lambda^{5} \ldots \\
\ldots+1.10115 \lambda^{6}-0.435933 \lambda^{7}
\end{array}\right] \\
& K_{c}=\left(\frac{1+3.867 \lambda-1.907 \lambda^{2}-0.834 \lambda^{3}}{1+1.867 \lambda-0.741 \lambda^{2}}\right)
\end{aligned}
$$

where $\lambda=r_{i} / r_{p}$.

For the viscosity inside the pore, the model proposed by Wesolowska et al. $^{\left[{ }^{32]}\right.}$ is adopted, leading to:

$$
\bar{\eta}=\left[\frac{(1-y)^{4}}{\eta_{\mathrm{p}}}+\frac{\left(4 y-6 y^{2}+4 y^{3}-y^{4}\right)}{10 \eta_{\mathrm{p}}}\right]^{-1}
$$

where $y=d / r_{\mathrm{p}}$, and $d=0.28 \mathrm{~nm}$.

Through this set of relations, the retention coefficient, $R$, is a function of the pore radius, $r_{p}$. From a set of data of, $J_{V}$ and $R$, the pore radius could be estimated as the free parameter in the best fit to Eq. (17). In this work, instead of using the whole data set to estimate a unique $r_{\mathrm{p}}$ average value, each pair of values $\left(J_{v}, R\right)$ were used to calculate the corresponding $r_{\mathrm{p}}$ from Eq. (17). As the filtration process modify flux rate and retention coefficient along the process, $r_{\mathrm{p}}$ changes with time too.

\section{Materials and methods.}

\subsection{Membranes and experimental set-up.}

Three different nanofiltration flat sheet membranes were tested: NF270 from Dow - Filmtec (the flatsheets were kindly supplied by the manufacturer); 
HL from GE Water \& Process Technologies and KMS SR3 from Koch Membrane systems. The main characteristics of them are shown in Table 1.

\section{TABLE 1}

The experimental set-up used in this study is described in sufficient detail elsewhere $^{[23]}$ thus only a brief summary is provided here. All the experiments were performed in a batch unit without dilution with a stainless steel flat sheet crossflow module with a single channel of length $L=110 \mathrm{~mm}$; height $H=0.5 \mathrm{~mm}$ and width $W=60 \mathrm{~mm}$. These dimensions provide a membrane surface area $A_{m}=6.6 \cdot 10^{-3} \mathrm{~m}^{2}$.

The operating conditions for every filtration processes were: feed temperature of $20^{\circ} \mathrm{C}$, applied pressure of $35 \cdot 10^{5} \mathrm{~Pa}$ and retentate recirculation flow of $5 \mathrm{~L} / \mathrm{min}$. According to the dimensions of the channel, this supposes a feed tangential velocity on the membrane surface of $2.78 \mathrm{~m} / \mathrm{s}$.

\subsection{Synthetic solution and commercial grape must.}

Two NF processes were performed for each membrane. Firstly, a synthetic solution prepared in the laboratory containing the main low molecular weight compounds (LMW) of grape must was filtered. These are namely glucose (Glu), fructose (Fru), malic and tartaric acids, potassium, sodium, calcium and magnesium. The concentrations of this synthetic solution were the same that those reported in a previous work ${ }^{[23]}$

Then it was carried out the filtration of commercial red must, which also contains high molecular weight compounds (HMW) such as polyphenols, polysaccharides and proteins. Attempting to reproduce the same conditions as in the first filtrate, the experiments with grape must were made using a brand new membrane flat sheet. 
In this way, it was possible to analyze individually the influence of these HMW and LMW on the permeate flux decline, the true retention, the fouling mechanism and on the resistances to the permeate flux.

\subsection{Experimental protocol.}

The experimental protocol can be summarized as:

1. Membrane compaction was performed during one hour using Milli-Q water at $35 \cdot 10^{5} \mathrm{~Pa}, 20^{\circ} \mathrm{C}$ and a recirculation flow of $5 \mathrm{~L} / \mathrm{min}$, in order to avoid irreversible changes during operation. Under these conditions water permeability was determined. This measurement was repeated before and after all filtration and cleaning steps.

2. The membrane was soaked in the synthetic solution for 12 hours at 20$25^{\circ} \mathrm{C}$. This was done to allow an initial deposition of foulants.

3. Nanofiltration of the synthetic solution of LMW at the operating conditions mentioned in 3.1.

4. Then, the membrane was cleaned with soft water at low pressure, under the same operating conditions of temperature and recirculation flow, during one hour sending both permeate and retentate to the drain. Afterwards it was rinsed with Milli-Q water using at least a volume equal to the system hold-up volume and sending the permeate and retentate to the drain too. Finally, the hydraulic permeability was measured.

5. Compaction and determination of hydraulic permeability of a new membrane sheet (step 1).

6. Soaking of the membrane in commercial red must during 12 hours with the same purpose as in step 2.

7. Nanofiltration of commercial red must at the operating conditions mentioned in 3.1 .

8. A two stage membrane cleaning procedure consisting in a water rinse step followed by the use of a tensoactive solution of $0.1 \%$ sodium dodecyl sulfate as described in ${ }^{[23]}$. After each step, hydraulic permeability was measured. 
In each nanofiltration process, the permeate flux values were determined by recording the time required to collect a known volume of filtrate $(10 \mathrm{~mL})$, first every 15 minutes and when the flux reached more stable values, every 45 minutes. At the same time samples of permeate and retentate were taken in order to determine their glucose and fructose content by liquid chromatography.

As mentioned, the filtration of both the synthetic solution and the red must were carried out in a batch concentration mode. The permeate was sent to the thermostated permeate vessel in order to collect it and the retentate was recirculated to the thermostated feed vessel. The experiments were performed until the permeate flux decreased to a more or less constant value for a reasonable period of time (which depended on the membrane). The volumes filtered were of the order of $2.5 \mathrm{~L}$ of both, synthetic solution and red must.

\subsection{Deposition factor $(\gamma)$}

A significant issue is the extent to which the cross-flow operation may affect the particle deposition on the membrane surface and therefore the specific cake resistance. In the present investigation, a deposition factor $\gamma$ was estimated by determining the ratio of the true amount of must foulants deposited on each membrane surface over the theoretical one.

The true mass deposition was determined by calculating the mass difference between each fouled NF membrane and the respective new one. For this purpose, red must filtrations were performed using the three membranes.

Pieces of both, fouled and clean, for each membrane were dried under temperature $\left(70^{\circ} \mathrm{C}\right)$ and pressure $(25 \mathrm{mmHg})$ until measuring a constant weight and the mass difference was measured. These conditions were established by the OIV ${ }^{[29]}$ for grape and wine dry extract determination.

The theoretical cake mass was calculated by considering that all the dry extract of must filtrated was attached to the cake layer on the basis of the total permeate volume of each membrane test. 


\subsection{Analytical methods.}

The chromatography system used for the identification and quantification of glucose and fructose was composed of a Shimadzu ${ }^{\text {TM }}$ LC-9A HPLC apparatus, a Shimadzu ${ }^{\mathrm{TM}}$ Refractive Index device with a detector RID 6A, a Rheodyne ${ }^{\mathrm{TM}}$ injector with a $20 \mu \mathrm{L}$ loop and the software Class-VP ${ }^{\mathrm{TM}}$. Separation was carried out isocratically in $100 \%$ deionized water at a flow rate of 0.5 $\mathrm{mL} / \mathrm{min}$ at $85^{\circ} \mathrm{C}$ using a Supelco ${ }^{\mathrm{TM}}$ ion exchange guard column and a Supelcogel ${ }^{\mathrm{TM}} \mathrm{Pb}$ column.

\subsection{SEM and AFM microscopy.}

The surfaces of the membranes were imaged by Scanning Electron Microscopy, SEM. The samples were put on an aluminum plate and sheltered with a thin metal layer by a Polaron ${ }^{\mathrm{TM}}$ (SC7640 model) Sputter Coater. The electronic imaging device XL30 ES type EM (from Phillips ${ }^{{ }^{T M}}$ ) was used and several accelerating voltages were applied to reach different magnifications.

Topography of the active layers was also studied through AFM. Images were acquired in the tapping mode at room temperature, with a Nanoscope IIIA microscope from Digital Instruments (of the Veeco ${ }^{\mathrm{TM}}$ Metrology Group). The tip was an Olympus ${ }^{\mathrm{TM}}$ OTESPA7 made out of an etched silicon probe aluminum coated with a length of $14 \mu \mathrm{m}$ and an end with a radius of $7 \mathrm{~nm}$. This allowed the minimization of the undesirable convolution of the tip shape and the membrane surface topography. Images were processed by means of the Nanoscope software version 5.30r3.sr3.

\section{Results and discussion.}

\subsection{Permeate flux and permeability.}


As mentioned, hydraulic permeability, $L_{P}$, was determined before and after every filtration or cleaning process and for each membrane as the slope of the $J_{V}$ vs $\Delta p$ plot with Milli-Q water ${ }^{T M}$. From $L_{P}$ data, the initial and final membrane resistances were calculated for $R_{f}=0$ and $\Delta \pi=0$. Results are shown in Table 2. It is clear that after the filtration and rinse of the synthetic solution, water permeability was slightly reduced for the three membranes. The main differences were detected after must nanofiltration and cleaning procedure. The SR3 membrane presented the highest permeability recovery (93\%), followed by the $\mathrm{HL}$ membrane $(70 \%)$ and finally by NF270 (65\%). This means that SR3 has the most reversible fouling, presumably due to a less adhesion of molecules on the membrane surface or inside the pores.

TABLE 2

The permeate flux of the synthetic solution and red must filtrations for each membrane are plotted in Figure 2. In all cases, a decay of flux is observed. Here it can be noticed that the NF270 membrane has clearly the highest flux of the synthetic solution, followed by SR3 and HL. Bigger differences were appreciated mainly at the beginning of the red must NF, when the SR3 membrane presented the highest flux while NF270 and HL presented very similar fluxes, 3 times lower than that for the SR3. Besides, SR3 showed a less-sharp initial decline of flux (during around the initial $170 \mathrm{~min}=10.2 \cdot 10^{3} \mathrm{~s}$ ) followed by a very sharp flux decay. It is worth noting, that after a certain filtration time, the 3 membranes reached a more or less flat plateau around a quite similar low flux.

\section{Figure 2}

\subsection{Sugars retention and passage.}


True retentions of glucose and fructose have been evaluated. The corresponding results are shown in Figure $3 a$ (for the synthetic solution) and in Figure $3 b$ (for the commercial must) as a function of time.

Figure 3

Sugars retention remains practically constant during the synthetic solution filtration for the three membranes. Both sugars (glucose and fructose) were retained by all the membranes, especially by NF270 and SR3. NF270 presented the highest retention values (around 0.8) followed by $\mathrm{HL}$ (ranging from 0.65 to 0.72 ) and finally by SR3 (between 0.44 and 0.52 ); which is in accordance with the estimated radius for each of them, as we will show below.

These retentions do not agree with the nominal data shown in Table 1. According to them, the SR3 membrane is the most retentive one for $\mathrm{MgSO}_{4}$ while NF270 is the less retentive. This different salt rejection could be due to the charge of the membranes and/or to their hydrophillicity. Given that the three membranes have quite similar isoelectric points, around $\mathrm{pH}=3.5^{[33-35]}$, the difference must be mainly attributable to their contact angles. In fact, SR3 is the most hydrophobic membrane (see Table 1$)^{[34,36,37]}$, what should explain its high retention of a charged and hydrated salt as $\mathrm{MgSO}_{4}$.

However, as it is shown in Figure 3b, the presence of HMW compounds modifies the retention characteristics of the three membranes. The initial retention falls drastically, between 0.2 , for SR3 and 0.4 for NF270, keeping the same order, as for the synthetic solution, for the three membranes. Subsequent filtering leads to an increase in retention. This long time increase of retention occurs equally for the three membranes, although much steeply for SR3; this membrane and $H L$ present values of $R$ around 0.9 , well above the value $(0.8)$ around which the NF270 finally stabilizes.

This evolution, when HMW compounds are present, must be attributed to the formation and thickening of a gel layer on the membrane surface that acts as a pseudo-membrane which lowers the passage of sugars through the membrane by changing both: selectivity and permeability of the overall 
membrane. As seen in Figure 3b, the influence of this pseudo-membrane on the membrane retention is more significant in the case of SR3.

\subsection{Analysis of the fouling mechanisms.}

In order to analyze the fouling kinetics of both the synthetic solution and the red must filtrations in a quantitative way, the previously outlined fouling models ${ }^{[19,20]}$ have been used to fit the experimental data. The intermediate blocking model seems to be compatible with data corresponding to the filtration of the synthetic solutions and with the first steps of must filtration. The slopes of the synthetic solution fits for the intermediate model, given by Eq. (3), were similar for the three membranes. Note that, the slope is related with the area of the membrane blocked per unit of total volume flown (through $\kappa_{i}$ ). The values for $\kappa_{i}$ are shown in Table 3 . The highest $\kappa_{i}$ was obtained for $\mathrm{HL}$, followed by SR3 and finally by NF270.

\section{TABLE 3}

Figure $4 a$ shows, as an example, the plots of flux versus the total volume flown over time for the synthetic solution and red must filtration for SR3, fitted to the intermediate blocking model where it can be seen that the slope is much higher for the must than for the synthetic solution revealing a faster fouling kinetics. This should be due to the additional pore blocking caused by the high molecular weight compounds probably affecting the widest pores in the membrane. The corresponding kinetic constants for the three membranes and the synthetic solution are shown in Table 3.

In Figure 4b, the corresponding flux decay for the red must filtration is shown for the three membranes studied. The kinetic constants are also shown in Table 3. The fastest kinetics corresponds now to NF270 followed by HL and finally by SR3 - the order of decreasing initial sugars retention (see Figures 3a and $3 b)$. What seems reasonable, because more retention would lead to more deposition and consequently to faster flux decay. Note that $\kappa_{i}$ for NF270 was the lowest one (slowest kinetics) for the synthetic solution, while it is the highest 
(fastest kinetics) when HMW components are present (red must filtration). This increase in $\kappa_{i}$ for the NF270 should be due to a high affinity (chemical or electrostatic) of the membrane material to these high molecular weight components. Note too that the less blocked area (less $\kappa_{i}$ ) corresponds to SR3 when HMW compounds are present.

\section{Figure 4}

Eq. (4) corresponding to the "cake formation" mechanism is plotted in Figure 5. Here it is clearly seen that, for the three membranes, this mechanism is followed after the initial intermediate blocking during nanofiltration of must. In general, the three membranes suffer little pore blocking, especially SR3, where this mechanism seems to occur only during the first $30 \mathrm{~mL}$ of filtration. It is worth noting that in the three cases, the cake filtration mechanism seems to be divided into two steps: cake formation and cake formation with compaction. In any case both, the cake fouling steps, are faster for $\mathrm{HL}$ and the corresponding initial $\kappa_{c}$ is relatively low for SR3 while the final $\kappa_{C}$ is lower for NF270 (less compaction). The values of these kinetic constants are shown in Table 3.

\section{Figure 5}

\subsection{Microscopy.}

Figure 6 provides AFM pictures of an SR3 membrane before having been fouled (a) and afterwards (b). It seems clear that, after fouling, there is a quite compact thick cake layer that reduces extraordinarily the roughness.

\section{Figure 6}

In Figure 7, two SEM pictures of an HL membrane before and after fouling are showed. The two pictures correspond to a $20 \mu \mathrm{m}$ in size. The picture after fouling shows a small square area that was imaged previously to the big one but also after fouling. It seems clear that the electron beam damaged the cake layer. The same procedure on the unfouled membrane didn't leave any similar trace. 


\section{Figure 7}

\subsection{Resistances to the permeate flux.}

The resistances to $J_{V}$ due to the presence of LMW, $R_{f L M W}$, and HMW, $R_{f H M W}$, were determined and analyzed individually. The values of $R_{f L M W}$ for the synthetic solution were calculated according to Eqs. (2) and (4) with $R_{f H M W}=0$. The kinetics of $R_{f L M W}$ for each membrane during the filtration of the synthetic solution filtration is shown in Figure 8a. In this case, NF270 presented the lowest values of resistance due to fouling, followed by HL and by SR3. This was to be expected because this order appeared also in retention as was shown in Figure $3 a$. Higher retentions lead to increasing viscosity and osmotic pressure that resulted in higher resistance to flux and also to faster fouling according to their corresponding $\kappa_{i}$ in Table 3.

The correlation between $R_{f L M W}$ and the total sugar concentration (glucose and fructose) on the membrane surfaces, $C_{m T}$ is shown in Figure $8 \mathrm{~b}$. There, it can be seen that the correlation between $R_{f L M W}$ and $C_{m T}$ is practically linear, so it can be concluded that the resistance due to the accumulation of sugars on the membrane surface is proportional to their surface concentration. When $C_{m T}$ is similar for the three membranes (shadowed zone in Figure $8 b$ ) the SR3 membrane has the lowest resistance due to low molecular weight compounds, $R_{f L M W}$.

\section{Figure 8}

In the case of red must filtrations, the values of $R_{f L M W}$ were determined by the calculation of $C_{\mathrm{mT}}$ and the use of the correlation between $R_{f L M W}$ and $C_{m T}$ obtained for the synthetic solution. Replacing $R_{f L M W}$ in Eqs. (2) and (4), the values of $R_{\text {fHMW }}$ were determined for each membrane. Figure 9 shows the 
evolution, with the permeated volume, of the individual resistances due to fouling $\left(R_{f L M W}\right.$ and $\left.R_{f H M W}\right)$ and their sum $\left(R_{f}\right)$ for the three membranes. The figure shows that during most of the nanofiltration process there is no significant increase of $R_{f L M W}$ as was also the case for the synthetic solution. When filtering red musts, $R_{f L M W}$ remains practically constant in comparison to $R_{f H M W}$ which increases progressively until reaching a maximum beyond which there is a gradual small decrease. This mechanism is clearly followed by SR3 (Figure 9c). In all cases, $R_{f H M W}$ has more influence on the $J_{V}$ decrease, but this phenomenon seems to be lower for the SR3 membrane (Figure 9d). It is interesting to relate the cake fouling mechanism (Figure 5) with the resistances analysis (Figures 8 and 9).For the three membranes, the maximum $R_{f}$ (or $R_{f H M W}$ agrees fairly well with the beginning of the third fouling mechanism, where the cake starts to be compacted.

\section{Figure 9}

The specific cake resistance, $\alpha$ (total resistance divided by the mass deposited per unit membrane area) (see Eq. (9)), can help to somehow normalize the resistance to permeate flux due to the fouling generated by all the species present in red must $\left(R_{f}\right)$. As mentioned in section (2.4), there are two methods proposed for the estimation of the specific resistance. First, the specific cake resistance was calculated using Eq. (15) with $C_{b}$ evaluated by Eq. (14). For this purpose the numeric derivative of $\left(t / V_{P}\right)$ versus $V_{P}$ (Figure 5$)$ is performed to get $\kappa_{\delta} / 2$. In this calculation, all the cake formation mechanism (with and without compaction) was included. This was considered appropriate to describe the evolution of this parameter along the complete filtration. This differs from the methodology applied by Listiarini et al. ${ }^{[5,22]}$ where a linear regression was performed including only the portion corresponding to the cake filtration without compression. The deposition factor $\gamma$ was estimated for each membrane in order to take into account the incomplete foulant deposition giving the values shown in Table 3 . Note that $\gamma$ follows the tendency of $\kappa_{c}$ (second step). 
In Figure10, the evolution of this theoretical specific cake resistance as a function of the filtered volume is shown for each membrane. It is worth noting, that this parameter shows also a maximum followed by a slight decrease. The arrows correspond to the maximal values of $R_{f}$ for each membrane, which are near the zone of maxima for their specific cake resistance. As expected, the highest a was shown by HL followed by NF270. SR3 presented the lowest values during the first period of filtration (around $175 \mathrm{~mL}$ ) afterwards the resistance increases following the tendencies appearing in $\kappa_{\mathrm{c}}$ (see Figure 6). The results obtained for the resistances $\left(R_{f}\right.$ and $\left.\alpha\right)$ and even for the cake formation mechanism for SR3 explain its different flux decline trend. The less sharp flux decline during the beginning of red must nanofiltration is due to a lower cake formation with a low resistance $\left(R_{f}\right.$ and $\left.\alpha\right)$. But later, the progressive formation and mainly the compaction of the cake cause a flux decay to values close to those for the other two membranes.

\section{Figure 10}

The second method proposed is the estimation of the specific resistance $\alpha$ by using Eq. (19) and the experimental data. In Figure 11, the experimental total fouling resistance, in fact evaluated by using Eqs. (2) and (4), is compared with that evaluated from the specific resistance $\alpha$ by using Eqs. (9) and (15), for the SR3 membrane. It can be appreciated that the calculated $R_{f}$ follows the same trend as the experimental one. Note that around maximal resistances, the fouling kinetics give values for the resistance which are close to those directly obtained from the Hagen-Poiseuille equation. For shorter time filtrations, fouling kinetics underestimates (while for longer filtration times it overestimates) the total fouling resistance. This can be attributed to the fact that the fouling kinectics predicts a low cake formation and for longer periods the cake mass is over estimated. All in all, Figure 11 shows that the method proposed for the estimation of a using the fouling kinetics is acceptable since it describes the behavior of the experimental data specially in the period where the cake should be completely formed (before its compaction).

Figure 11 


\subsection{Evolution of pore radii.}

Pore radii were calculated as the value that minimizes the sum of squared residuals, $\left(R_{\mathrm{cal}}-R_{\mathrm{exp}}\right)^{2}$ for each data set, following the theoretical model explained in section 2.5. The fitted dependence between $R$ and $J_{V}$ obtained for the synthetic solution is plotted in Figure 12a using grey curves. Evidently, it is worth noting that the model was elaborated for a membrane with a constant average pore size, $r_{p}$; while it seems clear that in our case the effective mean pore size should change during the process of filtration due to the corresponding fouling process that includes pore blocking. Thus, the gray lines in Figure 12a correspond to the mean pore size of the membrane during the filtration process. The average deviation of the experimental results of retention from the theoretical retention curves in Figure 13a are evaluated and shown in Figure $13 \mathrm{~b}$ as a (linear) function of the kinetic constant of pore blocking (intermediate model). This shows that pore blocking is clearly the main phenomenon determining the variations of the actual effective pore radius.

Figure 12

During the permeation of must, there is a continuous increase of retention while flow decreases slowly. The progressive increase of retention is so high that it seems inappropriate to assume a single pore size. In this case the model has been applied to each measurement and the pore radius obtained as a function of the permeated volume. In Figure13, the effective pore radii evaluated from red must retention experiments are shown. It can be seen that there is a clear reduction of the effective pore size of the membrane (much slower, although a little larger, for the SR3 membrane). The mean pore radii for the synthetic solution are also shown here, for the sake of comparison, by horizontal lines. It is clearly observed that SR3 has the biggest pore radii, while the smallest ones appear in NF270. It can also be seen that the final pore radii for all the membranes are around $0.3 \mathrm{~nm}$. This fact indicates that effective 
radius is determined mainly by the cake formed on the membrane, more than by the membrane itself.

\section{Figure 13}

In spite of the final convergence in equivalent pore radii, initial details do show differences between the membranes, especially between SR3 and the other two. Figure13 shows a clear and pronounced drop of pore radii during the very first filtration moments for NF270 and HL. This happens as a consequence of the pore blocking explained in previous paragraphs. In contrast, for SR3, the pore radius does not show any significant initial decrease.

It appears clear that, for $\mathrm{HL}$ and NF270, pore blocking is the main factor determining the effective pore size with a final smooth additional reduction of pore size caused by the formation of the cake. The SR3 membrane is only slightly influenced by pore blocking with a final deep reduction due to the cake deposit and its compaction.

The arrows in Figure 13 correspond to the maximal resistances (Figure 8). Thus, it seems clear that maximal resistance occurs when the rhythm of decrease in pore size due to the cake formation starts to stabilize. This is especially apparent for the SR3 membrane.

\subsection{Pressure drops.}

Figure 14 shows the evolution of osmotic pressures and total effective pressures through: the global membrane system, the whole membrane and the cake itself.

Referring to the osmotic pressure (figure 14a), it increases for the cake and the global membrane system (that seems to be controlled by the cake) and decreases for the membrane itself with time (permeated volume). Note that the maximum rate of change for all the osmotic pressure terms appear when the fouling resistance $R_{f}$ has its maximum. Note that, in this case below, this maximum there are negative osmotic pressures for the cake what means that 
concentration is higher at the cake-membrane interface than at the feed-cake interface. After the maximum in resistance, all the interfaces from retentate to permeate correspond to decreases in concentration.

It seems clear (see Figure 14b) that the effective pressure drop through all the components of the membrane system and through the global system decrease with time (permeated volume) and that the maximal fouling resistance appears when these pressure drops decrease faster. It seems also clear that most of the effective pressure drop happens through the cake.

It can be concluded that, in our case, the maximum in the fouling resistance and the appearance of a change in cake kinetics appear when the osmotic pressures acts reducing substantially and quickly the effective pressure. Regarding to the passage from negative to positive osmotic pressures for the cake this would happen when the cake is completely build due to compression followed by a gradual (slower) compaction with an increase of the concentration at the feed-cake interface.

Note that, for the three membranes, when the osmotic pressure of the system starts to increase, sugars are retained at their maxima by the membrane system, as can be seen in Figure $3 b$. The highest $R_{f H M W}, R_{f L M W}$ and $R_{f}$ correspond to the beginning of the high retention plateau. This is especially clear for the SR3 membrane. So, as already mentioned, the sugar retention increase can be attributed to the formation of a cake layer on the membrane surface but its compression (and the corresponding osmotic pressure increase through the cake and subsequently through the membrane system) may be the cause of the significant retention increase that stops increasing when cake is completely built.

\section{Figure 14}

\section{Conclusions}

We have systematically studied the fouling mechanism and resistances and their influence on the performance of three different NF membranes proposed 
for sugar control of grape must. Moreover, a method was proposed for the analysis of the different osmotic pressure gradients through the resistances of the membrane system.

The fouling kinetics when high molecular weight compounds are present consists in three consecutive steps: An initial pore blocking step followed by a cake deposition phase and an increase in compression until arriving to compaction giving a slower kinetics. When the cake is completely well assembled, the sugar retention has arrived to the maximum and osmotic pressure of the system increases as to reduce the effective pressure. This later causes a decrease of cake resistance that was increasing until this moment. The evolution of retention and the effective pore size reveals the convergence of the effective pore size to that of the cake after compaction.

Moreover, when the cake is completely built, its compaction promotes an increase of the concentration at the feed-cake interface causing a passage from negative to positive osmotic pressures for the cake.

The analysis of the flux decay and retention of sugar in musts shows that, two of the three membranes studied, $\mathrm{HL}$ and SR3 are appropriate to reduce the content of sugar of red must. Specifically SR3 shows the best passage of sugar and less fouling.

\section{Acknowledgements}

Authors would like to thank the "Ministerio de Ciencia e Innovación (MCINN)" for the financial support of this work within the frame of the "Plan Nacional de I+D+l" through the research projects CTQ2012-31076 and MAT2011-25513. Also the Spanish "Junta de Castilla y Leon" has contributed through the project VA248U13.

C. Salgado wants to thank the Spanish Ministry of Education for the grant they gave to her within the frame of the "Plan Nacional de InvestigaciónCientífica, Desarrollo e InnovaciónTecnológica 2008-2011" (FPU grant: AP2010-5769) to complete her PhD. 
Authors acknowledge Dow-Filmtec for the free supply of membrane flatsheet samples to conduct this research.

\section{Nomenclature}

Roman

$\begin{array}{ll}A_{m} & \text { Membrane surface area }\left(\mathrm{m}^{2}\right) \\ A_{k} & \text { Membrane porosity } \\ C_{0, i} & \text { Feed concentration of the i-th component }\left(\mathrm{kg} \mathrm{m}^{-3}\right) \\ C_{b} & \text { Bulk concentration of foulants }\left(\mathrm{kg} \mathrm{m}^{-3}\right) \\ C_{f, i} & \text { Feed concentration of the i-th component }\left(\mathrm{kg} \mathrm{m}^{-3}\right) \\ C_{D E} & \text { Total dry extract of must }\left(\mathrm{kg} \mathrm{m}^{-3}\right) \\ C_{H M W} & \text { Concentration of HMW }\left(\mathrm{kg} \mathrm{m}^{-3}\right) \\ C_{m, i} & \text { Concentration of the i-th component on the bulk-cake interface }\end{array}$ (membrane active layer) $\left(\mathrm{kg} \mathrm{m}^{-3}\right)$

$C_{m, i}^{\prime} \quad$ Concentration of the i-th component on the membrane-cake interface $\left(\mathrm{kg} \mathrm{m}^{-3}\right)$

$C_{m T} \quad$ Total sugar concentration on the membrane active layer $\left(\mathrm{kg} \mathrm{m}^{-3}\right)$

$C_{p, i} \quad$ Permeate concentration of the i-th component $\left(\mathrm{kg} \mathrm{m}^{-3}\right)$

$C_{T, 0} \quad$ Initial total sugar concentration (glucose and fructose) of red must $\left(\mathrm{kg} \mathrm{m}^{-3}\right)$

$D_{i} \quad$ Diffusion coefficient of the i-th component $\left(\mathrm{m}^{2} \mathrm{~s}^{-1}\right)$

HMW High molecular weight compounds

$J_{v} \quad$ Permeate flux per unit of area through the membrane $\left(\mathrm{m}^{3} \mathrm{~m}^{-2} \mathrm{~s}^{-1}\right)$

$J_{v, 0} \quad$ Permeate flux per unit of area through the membrane at time $t=0$ $\left(\mathrm{m}^{3} \mathrm{~m}^{-2} \mathrm{~s}^{-1}\right)$

$K_{c} \quad$ Hindrance factor for convection given by Eq. (25) 
$K_{d} \quad$ Hindrance factor for diffusion given by Eq. (26)

$K_{m, i} \quad$ Mass transfer coefficient of the i-th component at semipermeable membranes $\left(\mathrm{m} \mathrm{s}^{-1}\right)$

LMW Low molecular weight compounds

$L_{p} \quad$ Water permeability $\left(\mathrm{m} \mathrm{Pa}^{-1} \mathrm{~s}^{-1}\right)$

$m_{c} \quad$ Mass of cake deposited on the membrane surface in $(\mathrm{kg})$

$m_{H M W} \quad$ Mass of HMW in the retentate $(\mathrm{kg})$

$M_{i} \quad$ Molar weight of the i-th component $\left(\mathrm{kg} \mathrm{mol}^{-1}\right)$

$m_{T R}(t) \quad$ Total sugar content of the retentate at the filtration time $\mathrm{t}(\mathrm{kg})$

$\mathrm{Pe} \quad$ Peclet number

$R \quad$ ideal gas constant $\left(1.987 \cdot 10^{-3} \mathrm{kcal} \mathrm{mol}^{-1} \mathrm{~K}^{-1}\right)$

$R_{f H M W} \quad$ Resistance due to fouling by high molecular weight compounds $\left(\mathrm{m}^{-1}\right)$

$R_{f L M W} \quad$ Resistance due to fouling by low molecular weight compounds $\left(\mathrm{m}^{-1}\right)$

$R_{f j} \quad$ General resistance due to fouling $\left(\mathrm{m}^{-1}\right)$

$R_{f} \quad$ Total resistance due to fouling $\left(\mathrm{m}^{-1}\right)$

$R_{i} \quad$ Membranes true retention for the i-th component

$R_{m} \quad$ Membrane resistance $\left(\mathrm{m}^{-1}\right)$

$r_{\mathrm{p}} \quad$ Pore radii $(\mathrm{nm})$

$r_{\mathrm{i}} \quad$ Radii of the i-th component $(\mathrm{nm})$

$T \quad$ Absolute temperature (K)

$t \quad$ Filtration time

$V_{0} \quad$ Initial volume of grape must $\left(\mathrm{m}^{3}\right)$

$V_{p} \quad$ Permeate volume $\left(\mathrm{m}^{3}\right)$

$V_{R}(t) \quad$ Volume of the retentate at the filtration time $t\left(\mathrm{~m}^{3}\right)$ 
Greek

$\begin{array}{ll}\alpha & \text { Specific cake resistance }\left(\mathrm{m} \mathrm{kg}^{-1}\right) \\ \gamma & \text { Deposition factor on the membrane surface } \\ \Delta p_{h, s} & \text { Applied transmembrane pressure }(\mathrm{Pa}) \\ \Delta p_{\text {eff,c }} & \text { Effective pressure drop across the cake }(\mathrm{Pa}) \\ \Delta p_{\text {eff, } m} & \text { Effective pressure drop across the membrane }(\mathrm{Pa}) \\ \Delta p_{\text {eff,s }} & \text { Effective pressure drop across the system }(\mathrm{Pa}) \\ \Delta p_{h, c} & \text { Hydraulic Pressure drop across the cake }(\mathrm{Pa}) \\ \Delta p_{h, m} & \text { Hydraulic Pressure drop across the membrane }(\mathrm{Pa}) \\ \Delta x & \text { Membrane thickness }(\mathrm{m}) \\ \Delta \pi_{c} & \text { Osmotic pressure gradient across the cake-active layer interface }\end{array}$
$(\mathrm{Pa})$

$\Delta \pi_{m} \quad$ Osmotic pressure gradient across the membrane-cake interface (Pa)

$\Delta \pi_{s} \quad$ Osmotic pressure gradient across the membrane system (Pa)

$\eta_{p} \quad$ Viscosity inside the membrane pore ( $\mathrm{Pa} \mathrm{s}$ )

$\kappa_{c} \quad$ Kinetic constant for the cake model $\left(\mathrm{s} \mathrm{m}^{-6}\right)$

$\kappa_{i} \quad$ Kinetic constant for the intermediate blocking model $\left(\mathrm{m}^{-1}\right)$

$\lambda \quad$ Ratio $r_{i} / r_{P}$

$\phi \quad$ Steric partition coefficient

\section{References}

(1) Kiss, I.; Vatai, G.; Bekassy-Molnar, E., Must concentrate using membrane technology. Desalination 2004, 162, (0), 295-300. 
(2) Versari, A.; Ferrarini, R.; Parpinello, G.P.; Galassi, S., Concentration of Grape Must by Nanofiltration Membranes. Food and Bioproducts Processing 2003, 81, (3), 275-278.

(3) García-Martín, N.; Perez-Magariño, S.; Ortega-Heras, M.; González-Huerta, C.; Mihnea, M.; González-Sanjosé, M.L.; Palacio, L.; Prádanos, P.; Hernández, A., Sugar reduction in musts with nanofiltration membranes to obtain low alcohol-content wines. Separation and Purification Technology 2010, 76, (2), 158-170

(4) Garcia-Martin, N.; Perez-Magarino, S.; Ortega-Heras, M.; Gonzalez-Huerta, C.; Mihnea, M.; Gonzalez-Sanjose, M.L.; Palacio, L.; Pradanos, P.; Hernandez, A., Sugar reduction in white and red musts with nanofiltration membranes. Desalination and water treatment 2011, 27, (1-3), 167-174.

(5) Listiarini, K.; Chun, W.; Sun, D.D.; Leckie, J.O., Fouling mechanism and resistance analyses of systems containing sodium alginate, calcium, alum and their combination in dead-end fouling of nanofiltration membranes. Journal of Membrane Science 2009, 344, (1-2), 244-251.

(6) Sioutopoulos, D.C.; Karabelas, A.J.; Yiantsios, S.G., Organic fouling of RO membranes: Investigating the correlation of RO and UF fouling resistances for predictive purposes. Desalination 2010, 261, (3), 272-283

(7) Ruth, B.F., Studies in Filtration III. Derivation of General Filtration Equations. Industrial \& Engineering Chemistry 1935, 27, (6), 708-723

(8) M J Matteson, C.O., Filtration: Principles and Practices, Second Edition, Revised and Expanded; Editor Ed.^^ds.;Marcel Dekker: New York, 1987.

(9) Tiller, F.M., The role of porosity in filtration part 3: Variable-pressure-variablerate filtration. AIChE Journal 1958, 4, (2), 170-174

(10) Tiller, F.M., The role of porosity in filtration. Numerical methods for constant rate and constant pressure filtration based on Kozeny's law. Chem. Eng. Prog. 1953, 49, (9), 467-479.

(11) Tiller, F.M., The role of porosity in filtration. Part 2. Analytical equations for constant rate filtration. Chem. Eng. Prog. 1955, 51, (6), 282-290. 
(12) Tiller, F.M.; Cooper, H.R., The role of porosity in filtration: IV. Constant pressure filtration. AlChE J. 1960, 6, (4), 595-601.

(13) Tien, C.; Bai, R., An assessment of the conventional cake filtration theory. Chemical Engineering Science 2003, 58, (7), 1323-1336

(14) Vorobiev, E., Derivation of filtration equations incorporating the effect of pressure redistribution on the cake-medium interface: A constant pressure filtration. Chemical Engineering Science 2006, 61, (11), 3686-3697

(15) Hermans, P.H.; Bredee, H.L., Zur kenntnis der filtrationsgesetze. Rec. Trav. Chim. 1935, 54, (9), 680-700.

(16) Gonsalves, V.E., A critical investigation on the viscose filtration process. Recueil des Travaux Chimiques des Pays-Bas 1950, 69, (7), 873-903

(17) Grace, H.P., Structure and performance of filter media. I. The internal structure of filter media. AIChE Journal 1956, 2, (3), 307-315

(18) Shirato, M.; Aragaki, T.; Iritani, E., Blocking filtration laws for filtration of powerlaw non-Newtonian fluids. J. Chem. Eng. Japan 1979, 12, (2), 162-164.

(19) Bowen, W.R.; Calvo, J.I.; Hernández, A., Steps of membrane blocking in flux decline during protein microfiltration. Journal of Membrane Science 1995, 101, (1-2), 153-165

(20) Herrero, C.; Prádanos, P.; Calvo, J.I.; Tejerina, F.; Hernández, A., Flux Decline in Protein Microfiltration: Influence of Operative Parameters. Journal of Colloid and Interface Science 1997, 187, (2), 344-351

(21) Schippers, J.C.; Verdouw, J., The modified fouling index, a method of determining the fouling characteristics of water. Desalination 1980, 32, (0), 137-148.

(22) Listiarini, K.; Sun, D.D.; Leckie, J.O., Organic fouling of nanofiltration membranes: Evaluating the effects of humic acid, calcium, alum coagulant and their combinations on the specific cake resistance. Journal of Membrane Science 2009, 332, $(1-2), 56-62$. 
(23) Salgado, C.; Palacio, L.; Carmona, F.J.; Hernández, A.; Prádanos, P., Influence of low and high molecular weight compounds on the permeate flux decline in nanofiltration of red grape must. Desalination 2013, 315, 124-134

(24) Kozinski, A.A.; Lightfoot, E.N., Ultrafiltration of proteins in stagnation flow. AlChE Journal 1971, 17, (1), 81-85.

(25) Goldsmith, R.L., Macromolecular Ultrafiltration with Microporous Membranes. Industrial \& Engineering Chemistry Fundamentals 1971, 10, (1), 113-120

(26) Jonsson, G., Boundary layer phenomena during ultrafiltration of dextran and whey protein solutions. Desalination 1984, 51, (1), 61-77

(27) Wijmans, J.G.; Nakao, S.; Smolders, C.A., Flux limitation in ultrafiltration: Osmotic pressure model and gel layer model. Journal of Membrane Science 1984, 20, (2), $115-124$

(28) Sioutopoulos, D.C.; Yiantsios, S.G.; Karabelas, A.J., Relation between fouling characteristics of RO and UF membranes in experiments with colloidal organic and inorganic species. Journal of Membrane Science 2010, 350, (1-2), 62-82

(29) OIV, Compendium of International Methods of Wine and Must Analysis; Editor Ed.^ ${ }^{\wedge}$ ds.;OIV: Paris, 2011.

(30) Silva, V.; Prádanos, P.; Palacio, L.; Calvo, J.I.; Hernández, A., Relevance of hindrance factors and hydrodynamic pressure gradient in the modelization of the transport of neutral solutes across nanofiltration membranes. Chemical Engineering Journal 2009, 149, (1-3), 78-86

(31) Dechadilok, P.; Deen, W.M., Hindrance Factors for Diffusion and Convection in Pores. Industrial \& Engineering Chemistry Research 2006, 45, (21), 6953-6959

(32) Wesolowska, K.; Koter, S.; Bodzek, M., Modelling of nanofiltration in softening water. Desalination 2004, 162, (0), 137-151.

(33) Oatley, D.L.; Llenas, L.; Pérez, R.; Williams, P.M.; Martínez-Lladó, X.; Rovira, M., Review of the dielectric properties of nanofiltration membranes and verification of the 
single oriented layer approximation. Advances in Colloid and Interface Science 2012, 173, 1-11.

(34) Rice, G.; Barber, A.R.; O’Connor, A.J.; Pihlajamaki, A.; Nystrom, M.; Stevens, G.W.; Kentish, S.E., The influence of dairy salts on nanofiltration membrane charge. Journal of Food Engineering 2011, 107, (2), 164-172

(35) Al-Amoudi, A.; Williams, P.; Mandale, S.; Lovitt, R.W., Cleaning results of new and fouled nanofiltration membrane characterized by zeta potential and permeability. Separation and Purification Technology 2007, 54, (2), 234-240.

(36) Mänttäri, M.; Pekuri, T.; Nyström, M., NF270, a new membrane having promising characteristics and being suitable for treatment of dilute effluents from the paper industry. Journal of Membrane Science 2004, 242, (1-2), 107-116

(37) Tang, C.Y.; Kwon, Y.-N.; Leckie, J.O., Effect of membrane chemistry and coating layer on physiochemical properties of thin film composite polyamide RO and NF membranes: II. Membrane physiochemical properties and their dependence on polyamide and coating layers. Desalination 2009, 242, (1-3), 168-182

\section{Figure captions}

Figure 1. Concentrations and osmotic pressures considered for the membrane system. Here $\Delta \pi_{c} \Delta \pi_{m}$ represent the osmotic pressure gradient across the cake-active layer interface and across the membrane-cake interface respectively; $C_{b}=$ Bulk concentration of foulants; $C_{m}$ Concentration on the membrane active layer; $C_{m}^{\prime}$ Concentration on the membrane-cake interface; and $C_{p}$ Permeate concentration

Figure 2. Permeate flux time evolution of red must (RM) and synthetic solution (SS) NF for each membrane. 
Figure 3. Glucose (Glu) and fructose (Fru) retentions as a function of time: (a) for the synthetic solution, (b) for red must ${ }^{[38]}$. Arrows correspond to maximum total fouling resistances.

Figure 4.- $\ln \left(J_{V}\right)$ versus $\left(V_{p} / A_{m}\right)$ : (a) The case of the SR3 membrane for the synthetic solution (SS) and for the red must (RM), (b) The case of the three membranes during red must NF as a comparison. Solid lines represent linear fit to the intermediate blocking mechanism zone of the data, corresponding to Eq. (3).

Figure 5.- $\left(t / V_{p}\right)$ versus $V_{p}$ for each membrane during red must NF. Open symbols correspond to intermediate zone; filled symbols correspond to cake formation mechanism zone.

Figure 6.- AFM pictures of the SR3 membrane before (a) and after (b) fouling. Note that after fouling roughness has decreased substantially.

Figure 7.- SEM pictures of the HL membrane before (a) and after (b) fouling. Note that after fouling a smaller square has been imaged and consequently the deposited layer eroded by the electron beam.

Figure 8.- Evolution of $R_{f L M W}$ for the synthetic solution for the three membranes: (a) as a function of filtration time, (b) as a function of total sugar concentration in the membrane surface $C_{m, T}$. Within the shadowed zone $C_{m T}$ is similar for the three membranes.

Figure 9.- Resistance due to fouling by low molecular weight, high molecular weight, and all compounds ( $R_{f L M W}, R_{f H M W}$ and $R_{f}$ respectively) in commercial red must versus the total permeated volume for: (a) NF270, (b) HL and (c) SR3 
membranes. (d) Comparison of the total fouling $\left(R_{f}\right)$ resistance for the three membranes. Arrows point to the respective maxima.

Figure 10.- Evolution of the specific cake resistance $(\alpha)$ as a function of the permeate volume $\left(V_{p}\right)$ for the three membranes during red must NF. Arrows correspond to the maximum total fouling resistance for each membrane (according to Figure 9d).

Figure 11.- Resistance due the total fouling $\left(R_{f}\right)$ for the SR3 membrane. Black triangles show the experimental resistance (see figure 9d) and white triangles refer to the calculated ones.

Figure 12.- (a) Retention versus $J_{V}$ for the synthetic solution filtration. Gray lines are the fits using theoretical model for pore radius calculation (solid for Glucose, dashed for fructose). Arrows indicate time line. (b) Mean deviation of the experimental results on retention as a function of the kinetic constant of pore blocking.

Figure 13.-Time evolution of pore radii calculated for each single data point of NF270 (Glu), $\mathbf{H L}(\mathrm{Glu}), \boldsymbol{\Delta}$ SR3 (Glu) of the red must NF process. Horizontal lines represent the average values obtained for the synthetic solution NF along the complete process. Arrows correspond to the maximum total fouling resistance for each membrane (according to Figure 9d).

Figure 14.- Osmotic pressures (a) and effective total pressures (b) through the membrane, cake and membrane system (membrane plus cake) for the SR3 membrane. 


\section{Tables}

Table 1. Main characteristics of the membranes.

\begin{tabular}{|c|c|c|c|c|c|c|c|}
\hline \multirow[t]{2}{*}{ Membrane } & \multirow[t]{2}{*}{ Manufacturer } & \multirow{2}{*}{$\begin{array}{c}\text { MWCO } \\
\text { (Da) }\end{array}$} & \multirow{2}{*}{$\begin{array}{c}\text { MgSO4 } \\
\text { Rejection } \\
\text { (\%) }\end{array}$} & \multicolumn{3}{|c|}{ Operating range } & \multirow{2}{*}{$\begin{array}{c}\text { Drop } \\
\text { Contac } \\
\text { angle } \\
\left({ }^{\circ}\right)\end{array}$} \\
\hline & & & & $\mathrm{pH}$ & $\begin{array}{c}\mathrm{P}\left(10^{5}\right. \\
\mathrm{Pa})\end{array}$ & $\mathrm{T}\left({ }^{\circ} \mathrm{C}\right)$ & \\
\hline NF270 & Dow & $200^{a}-400^{b}$ & $97^{\mathrm{c}, \mathrm{d}}$ & $3-10$ & $<41$ & $<45$ & $30^{9}$ \\
\hline & GE Water & $150-300$ & $98^{\mathrm{c}, \mathrm{e}}$ & $3-10$ & $<40$ & $<50$ & $27.5^{\mathrm{h}}$ \\
\hline SR3 & Koch & 200 & $99^{c, f}$ & $4-10$ & $<44.8$ & $<50$ & $49^{i}$ \\
\hline
\end{tabular}

${ }^{a[39],}{ }^{b[40]},{ }^{c}$ According to the information provided by the manufacturers, ${ }^{\mathrm{d}} \mathrm{MgSO}_{4} 2000 \mathrm{mg} / \mathrm{L}$ at $480 \mathrm{kPa},{ }^{e} \mathrm{MgSO}_{4} 2000 \mathrm{mg} / \mathrm{L}$ at $690 \mathrm{kPa},{ }^{\mathrm{f}} \mathrm{MgSO}_{4}$ $5000 \mathrm{mg} / \mathrm{L}$ at $655 \mathrm{kPa},{ }^{\mathrm{g}}{ }^{[36]}, \mathrm{h}[37],{ }^{\mathrm{i}}[34]$.

Table 2. Hydraulic permeability and resistance of the membranes, initial value and after nanofiltration and cleaning processes.

\begin{tabular}{|c|c|c|c|c|c|c|c|c|}
\hline \multirow{2}{*}{ Membrane } & \multicolumn{4}{|c|}{ Water Permeability $L_{p}\left(10^{-11} \mathrm{~m} / \mathrm{Pa} \mathrm{s}\right)$} & \multicolumn{4}{|c|}{ Membrane resistance $R_{\mathrm{m}}\left(10^{13} \mathrm{~m}^{-1}\right)$} \\
\hline & $\begin{array}{l}\text { Before } \\
\text { filtration }\end{array}$ & $\begin{array}{l}\text { After } \\
\text { synthetic } \\
\text { solution rinse }\end{array}$ & $\begin{array}{l}\text { After } \\
\text { must } \\
\text { rinse }\end{array}$ & $\begin{array}{l}\text { After must } \\
\text { cleaning with } \\
\text { SDS }\end{array}$ & $\begin{array}{l}\text { Before } \\
\text { filtration }\end{array}$ & $\begin{array}{l}\text { After } \\
\text { synthetic } \\
\text { solution rinse }\end{array}$ & $\begin{array}{l}\text { After } \\
\text { must } \\
\text { rinse }\end{array}$ & $\begin{array}{l}\text { After must cleaning } \\
\text { with SDS }\end{array}$ \\
\hline NF270 & 3.84 & 3.34 & 2.10 & 2.45 & 2.60 & 2.98 & 4.75 & 4.07 \\
\hline & 3.70 & 3.35 & 2.21 & 2.56 & 2.69 & 2.98 & 4.52 & 3.90 \\
\hline KMS SR3 & 2.18 & 2.10 & 1.44 & 1.97 & 4.57 & 4.74 & 6.92 & 5.06 \\
\hline
\end{tabular}

Table 3.Kinetic constants for fouling and the deposition factor $\gamma$.

\begin{tabular}{|c|c|c|c|c|c|}
\hline \multirow[b]{2}{*}{ Membrane } & \multicolumn{2}{|c|}{$\underset{\left(m^{-1}\right)}{\boldsymbol{K}_{\mathbf{i}}}$} & $\begin{array}{c}\kappa_{\mathrm{c}}(\text { (initial }) \\
\left(10^{11} \mathrm{~s} \mathrm{~m}^{-6}\right)\end{array}$ & $\begin{array}{c}\kappa_{c}(\text { final }) \\
\left(10^{11} \mathrm{~s} \mathrm{~m}^{-6}\right)\end{array}$ & \\
\hline & $\begin{array}{c}\text { SS } \\
\text { global }\end{array}$ & $\begin{array}{c}\mathrm{RM} \\
\text { initial }\end{array}$ & & RM & $\left(10^{-3}\right.$ dimensionless $)$ \\
\hline SR3 & 8.61 & 88.17 & 1.60 & 8.92 & 1.30 \\
\hline HL & 8.65 & 100.35 & 11.62 & 19.60 & 3.56 \\
\hline NF270 & 6.80 & 120.18 & 5.40 & 6.84 & 1.04 \\
\hline
\end{tabular}


Figure 1. Concentrations and osmotic pressures considered for the membrane system. Here $\Delta \Pi c$ $\Delta \Pi \mathrm{m}$ represent the osmotic pressure gradient across the cake-active layer interface and across the membrane-cake interface respectively; $\mathrm{Cb}=$ Bulk concentration of foulants; $\mathrm{Cm}$ Concentration on the membrane active layer; C'm Concentration on the membrane-cake interface; and Cp Permeate concentration

$254 \times 190 \mathrm{~mm}(96 \times 96 \mathrm{DPI})$ 


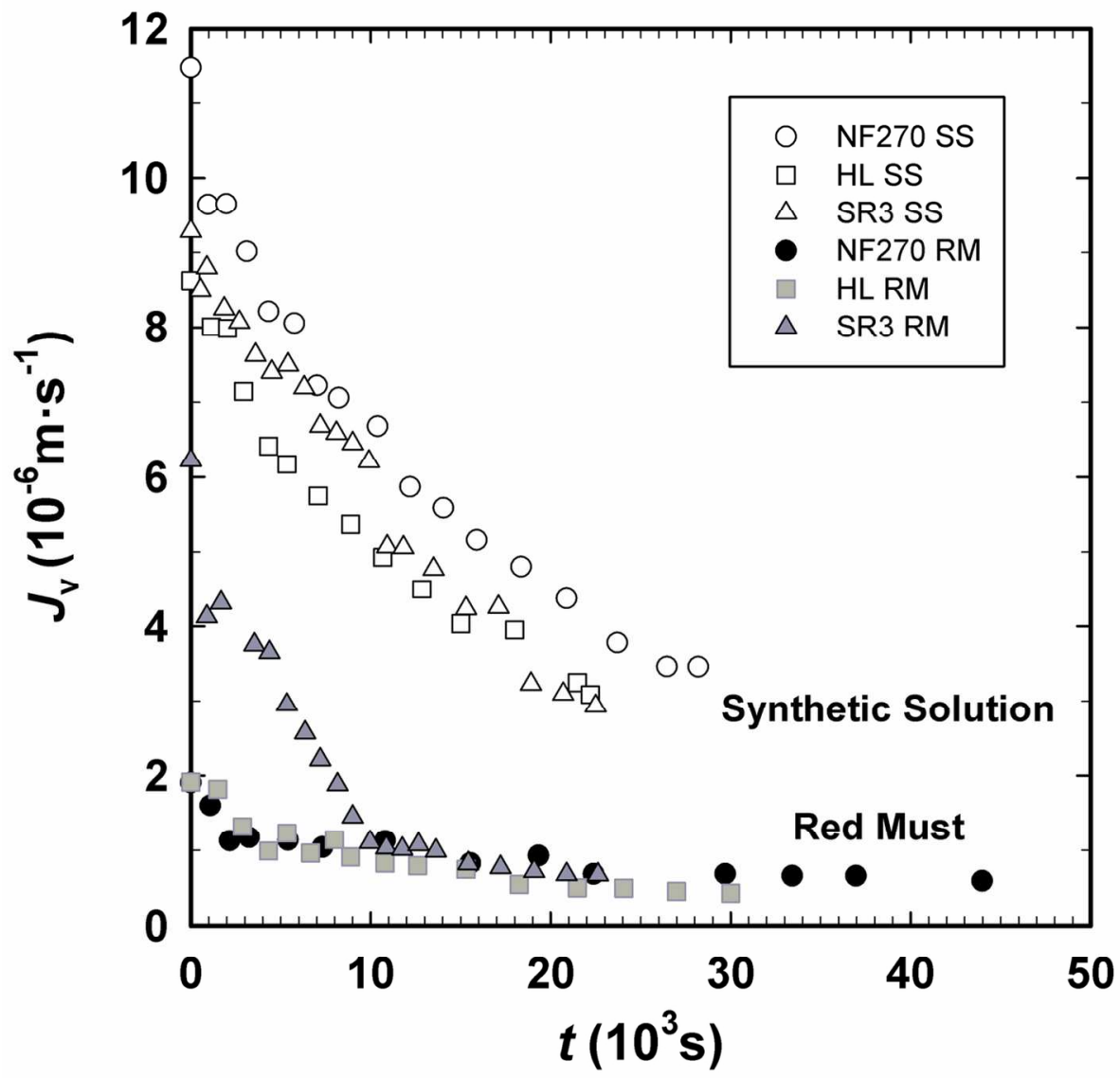

Figure 2. Permeate flux time evolution of red must (RM) and synthetic solution (SS) NF for each membrane. $124 \times 113 \mathrm{~mm}(300 \times 300 \mathrm{DPI})$ 

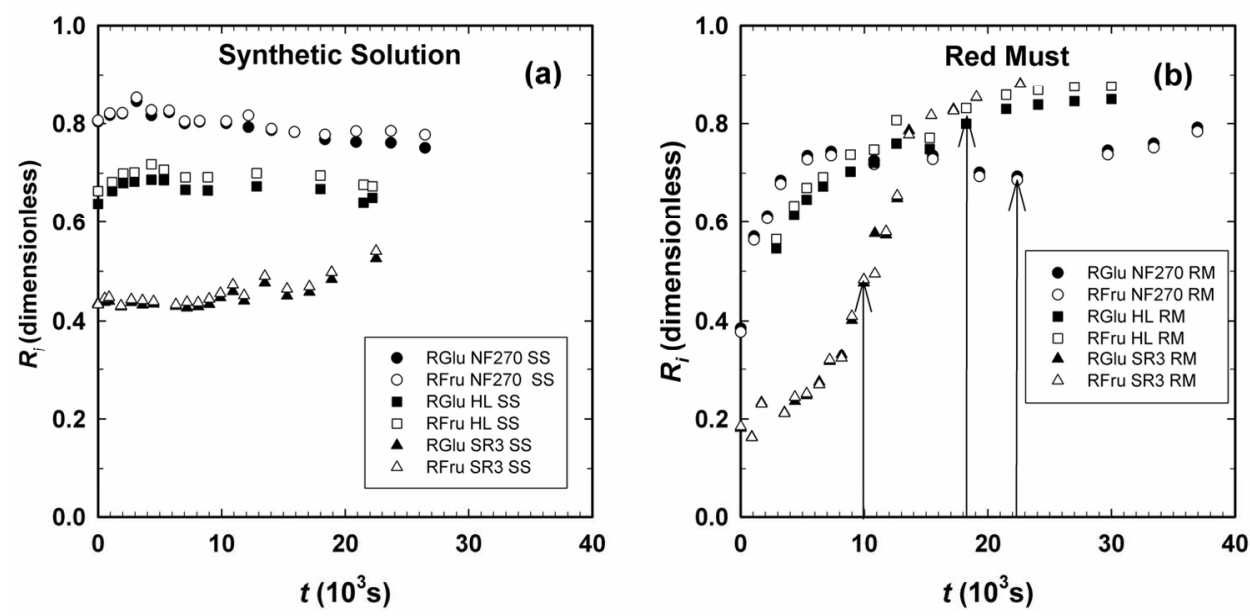

Figure 3. Glucose (Glu) and fructose (Fru) retentions as a function of time: (a) for the synthetic solution, (b) for red must [38]. Arrows correspond to maximum total fouling resistances. $134 \times 68 \mathrm{~mm}(300 \times 300 \mathrm{DPI})$ 

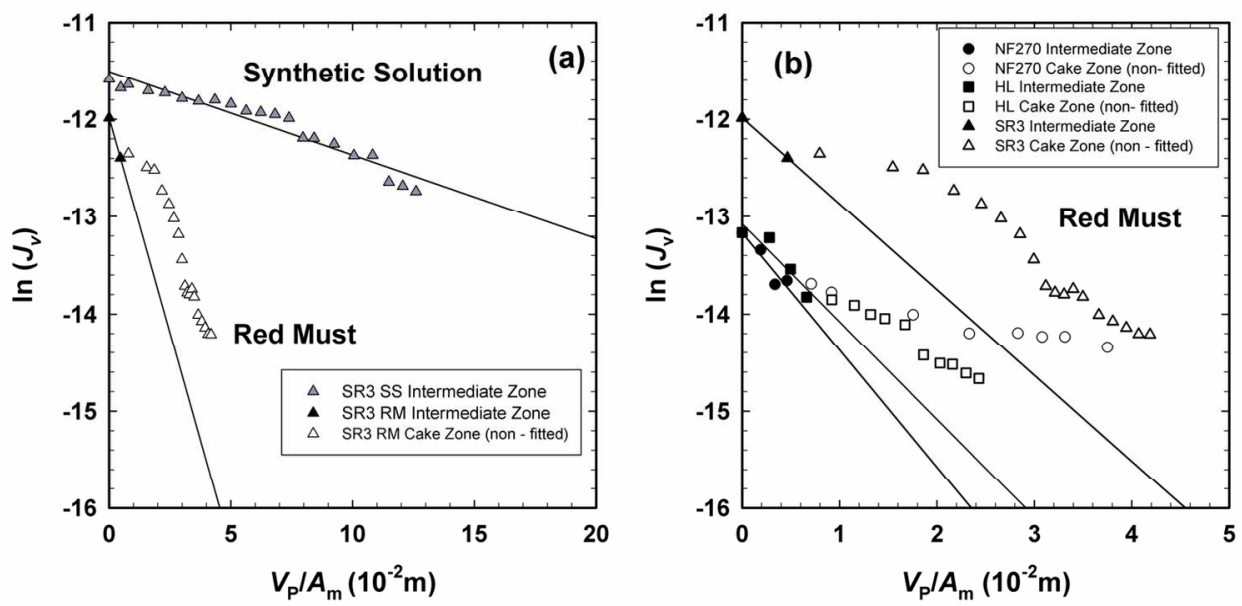

Figure 4. $\ln (\mathrm{JV})$ versus (Vp/Am): (a) The case of the SR3 membrane for the synthetic solution (SS) and for the red must (RM), (b) The case of the three membranes during red must NF as a comparison. Solid lines represent linear fit to the intermediate blocking mechanism zone of the data, corresponding to Eq. (3). $137 \times 70 \mathrm{~mm}(300 \times 300 \mathrm{DPI})$ 


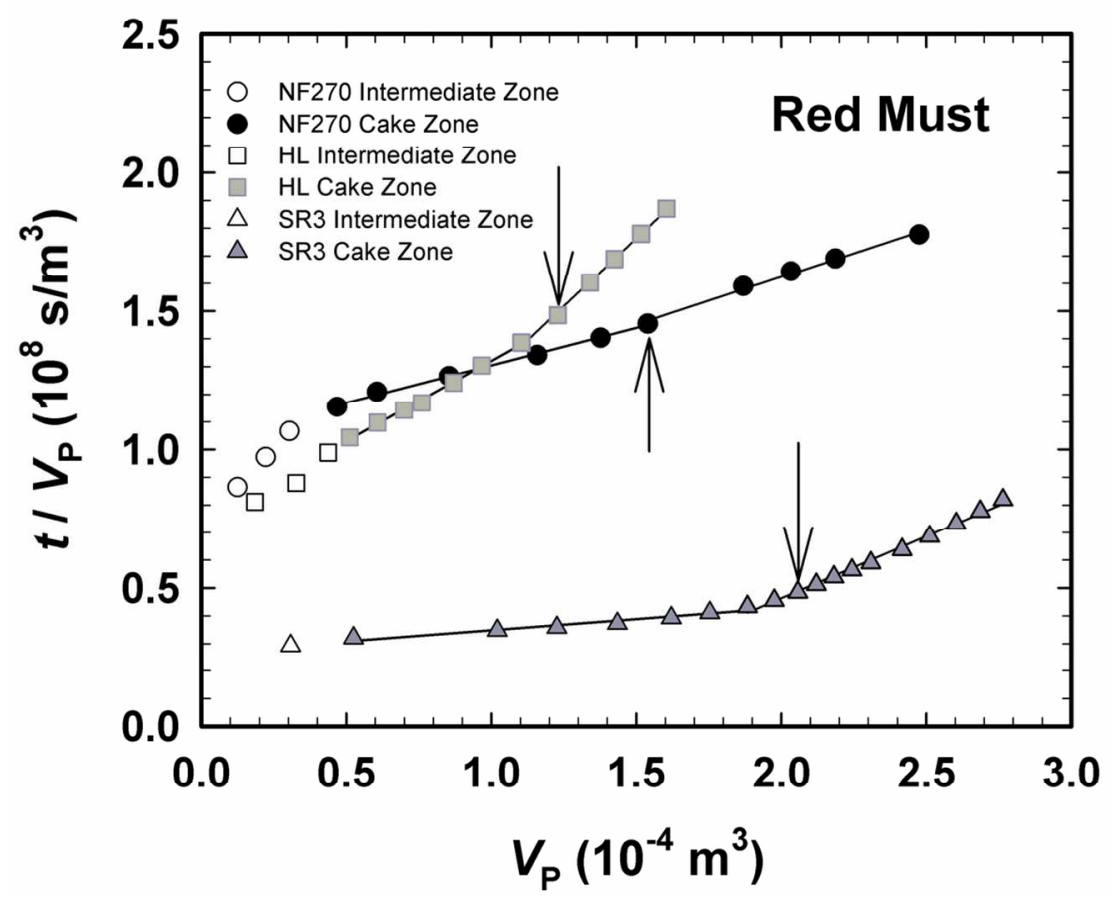

Figure 5. (t/Vp) versus Vp for each membrane during red must NF. Open symbols correspond to intermediate zone; filled symbols correspond to cake formation mechanism zone. $117 \times 91 \mathrm{~mm}(300 \times 300 \mathrm{DPI})$ 
Figure 6. AFM pictures of the SR3 membrane before (a) and after (b) fouling. Note that after fouling roughness has decreased substantially. $243 \times 120 \mathrm{~mm}(96 \times 96$ DPI) 
Figure 7. SEM pictures of the HL membrane before (a) and after (b) fouling. Note that after fouling a smaller square has been imaged and consequently the deposited layer eroded by the electron beam.

\section{$254 \times 190 \mathrm{~mm}(96 \times 96 \mathrm{DPI})$}



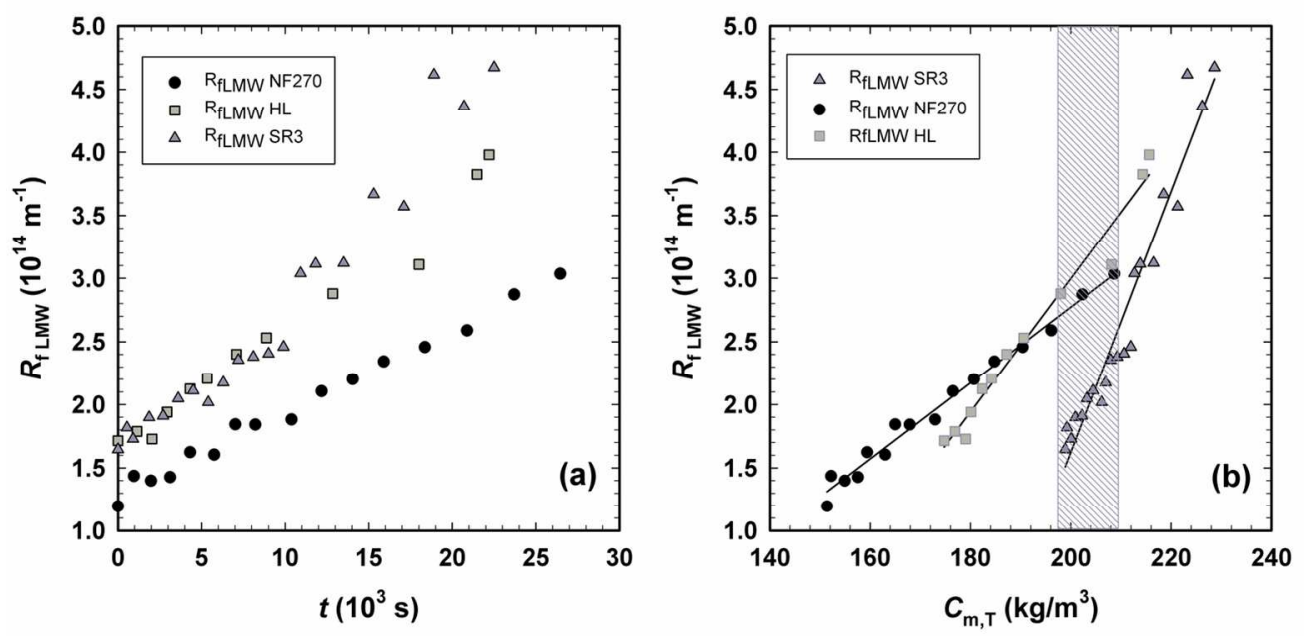

Figure 8. Evolution of RfLMW for the synthetic solution for the three membranes: (a) as a function of filtration time, (b) as a function of total sugar concentration in the membrane surface $\mathrm{Cm}, \mathrm{T}$. Within the shadowed zone $\mathrm{CmT}$ is similar for the three membranes.

$131 \times 66 \mathrm{~mm}(300 \times 300 \mathrm{DPI})$ 

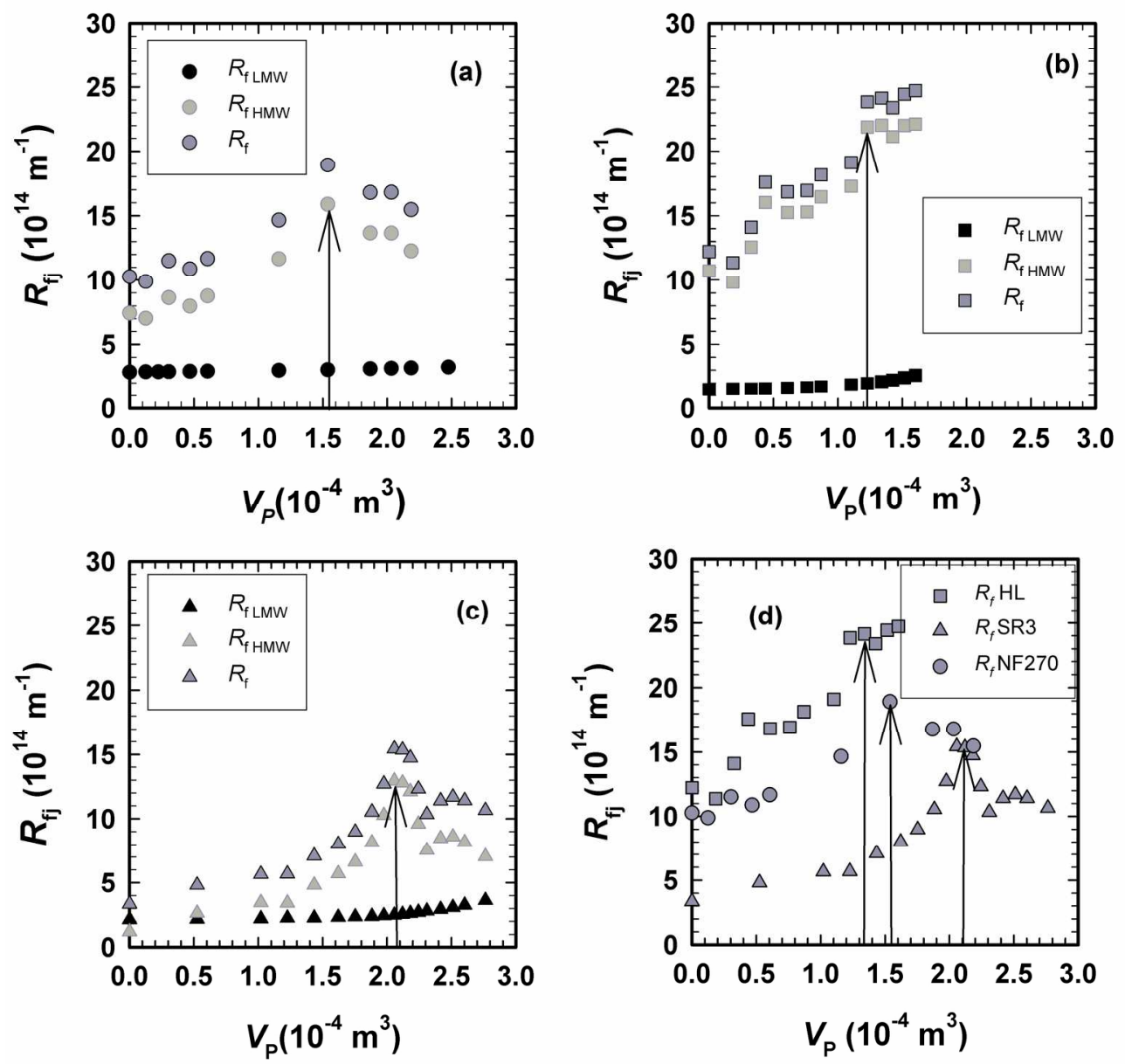

Figure 9. Resistance due to fouling by low molecular weight, high molecular weight, and all compounds (RfLMW, RfHMW and Rf respectively) in commercial red must versus the total permeated volume for: (a) NF270, (b) HL and (c) SR3 membranes. (d) Comparison of the total fouling (Rf) resistance for the three membranes. Arrows point to the respective maxima. $177 \times 177 \mathrm{~mm}(300 \times 300 \mathrm{DPI})$ 


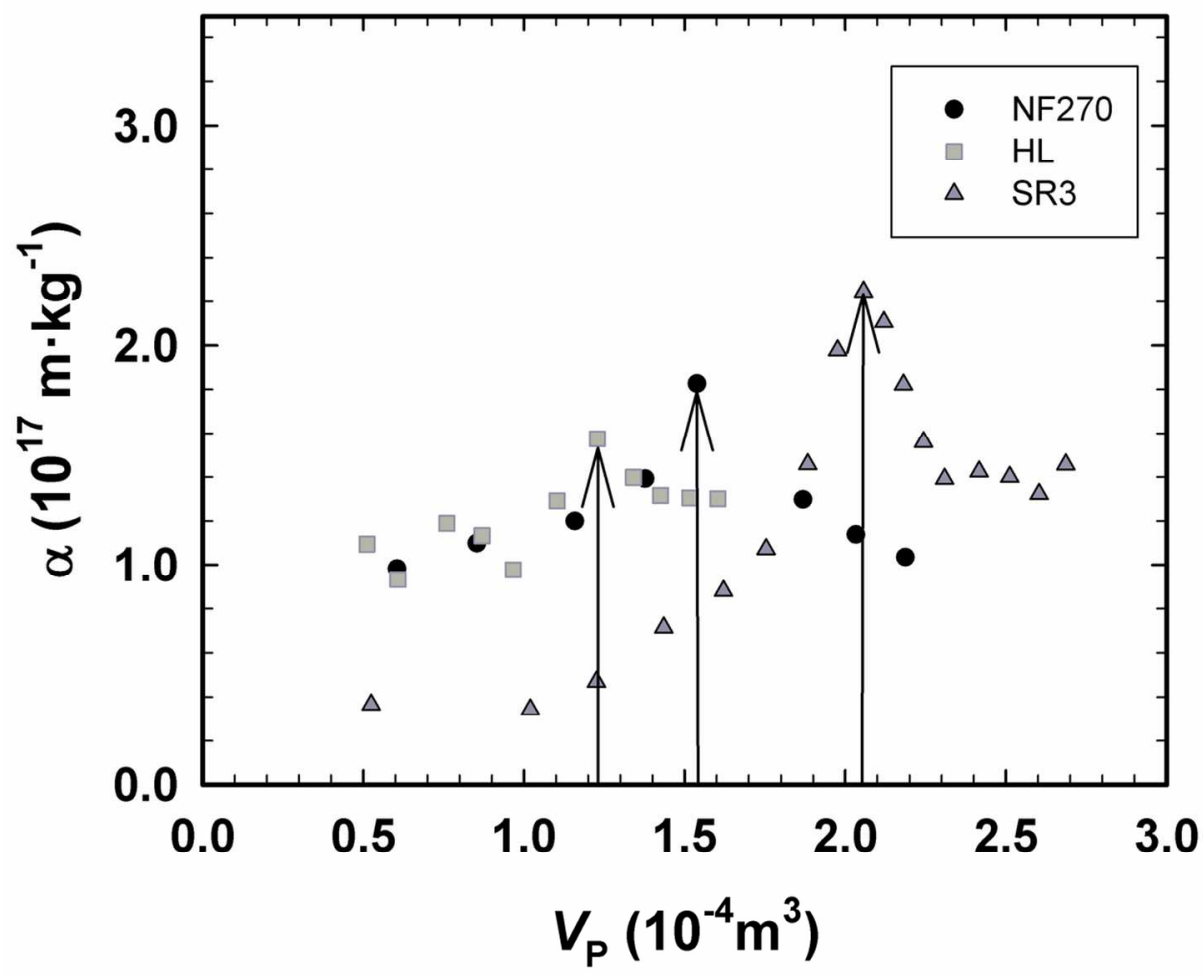

Figure 10. Evolution of the specific cake resistance (a) as a function of the permeate volume (Vp) for the three membranes during red must NF. Arrows correspond to the maximum total fouling resistance for each membrane (according to Figure 9d). $115 \times 97 \mathrm{~mm}(300 \times 300$ DPI $)$ 


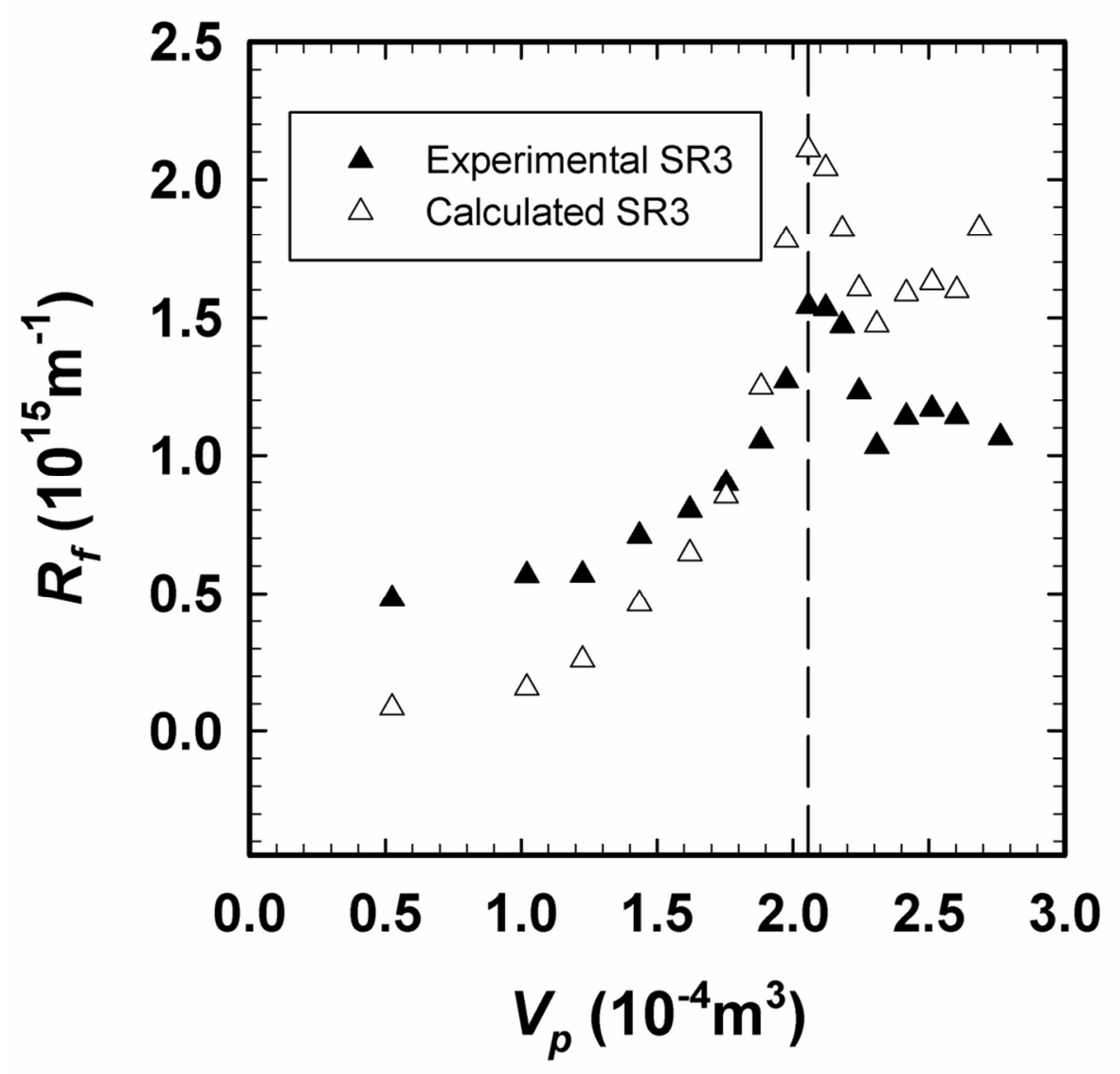

Figure 11. Resistance due the total fouling (Rf) for the SR3 membrane. Black triangles show the experimental resistance (see figure $9 \mathrm{~d}$ ) and white triangles refer to the calculated ones. $111 \times 108 \mathrm{~mm}(300 \times 300 \mathrm{DPI})$ 

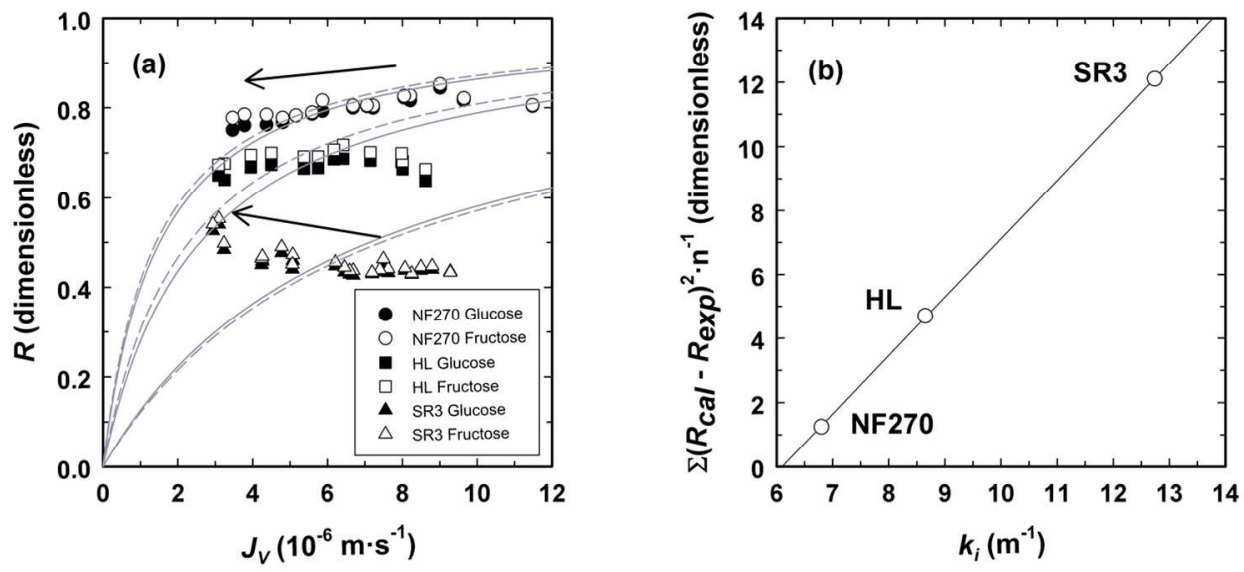

Figure 12. (a) Retention versus JV for the synthetic solution filtration. Gray lines are the fits using theoretical model for pore radius calculation (solid for Glucose, dashed for fructose). Arrows indicate time line. (b) Mean deviation of the experimental results on retention as a function of the kinetic constant of pore blocking.

$127 \times 62 \mathrm{~mm}(300 \times 300 \mathrm{DPI})$ 


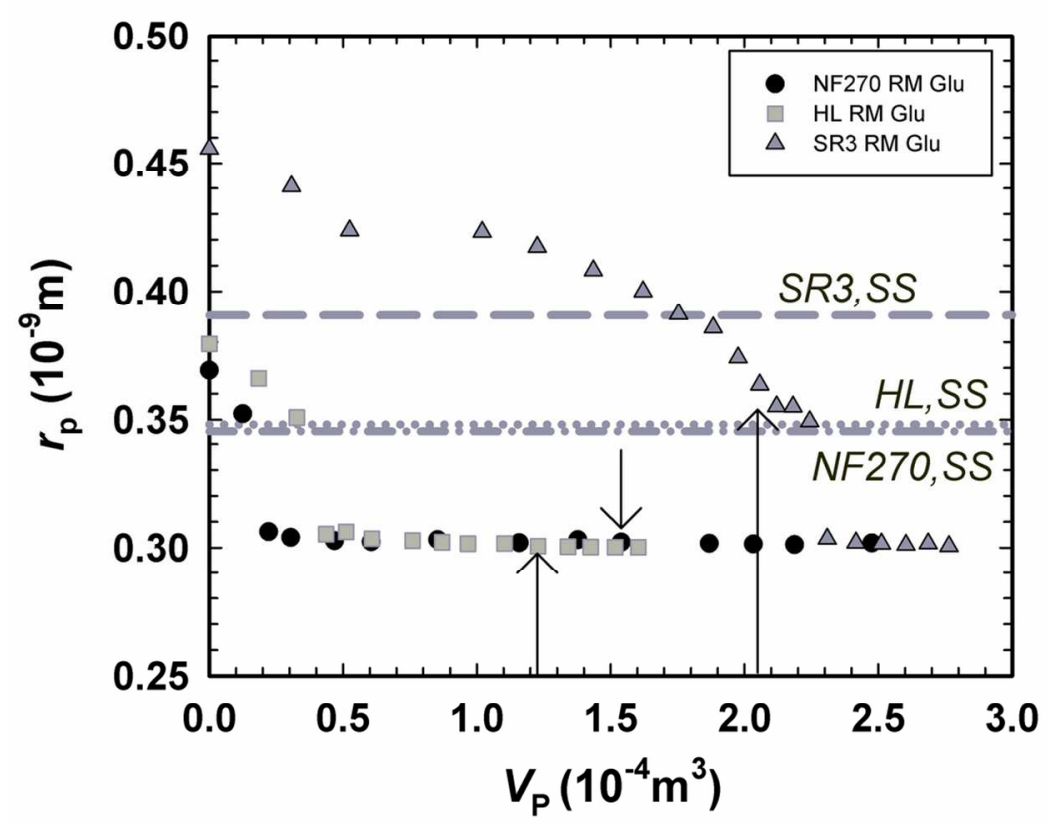

Figure 13. Time evolution of pore radii calculated for each single data point of $\circ$ NF270 (Glu), $\square \mathrm{HL}(\mathrm{Glu}), \Delta$ SR3 (Glu) of the red must NF process. Horizontal lines represent the average values obtained for the synthetic solution NF along the complete process. Arrows correspond to the maximum total fouling resistance for each membrane (according to Figure $9 \mathrm{~d}$ ) $\bullet \bullet \bullet \Delta \Delta \Delta$ $115 \times 82 \mathrm{~mm}(300 \times 300$ DPI $)$ 

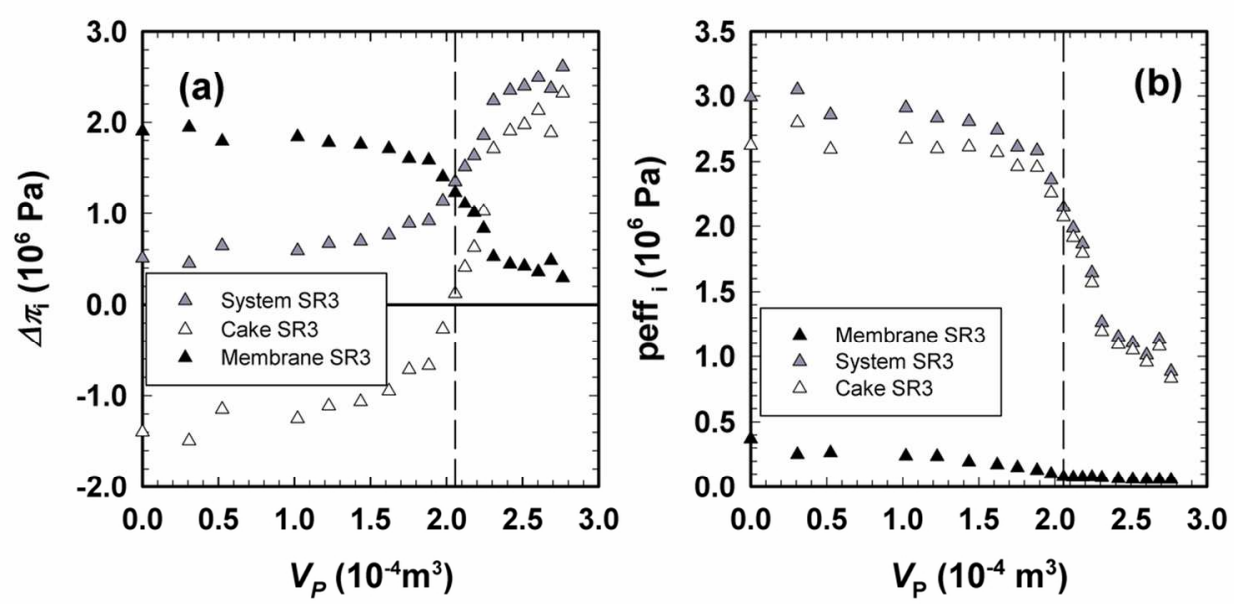

Figure 14. Osmotic pressures (a) and effective total pressures (b) through the membrane, cake and membrane system (membrane plus cake) for the SR3 membrane.

\section{$111 \times 57 \mathrm{~mm}(300 \times 300$ DPI $)$}

